\title{
Effects of dietary supplementation of chitosan on dry matter intake and blood parameters for dry dairy cows*
}

\author{
Q.H. Liu ${ }^{1,2}$, X.W. Liang ${ }^{2,3}$ and G.L. Wang ${ }^{1}$ \\ ${ }^{1}$ College of Animal Science and Technology, Nanjing Agricultural University \\ Nanjing 210095, Jiangsu, P.R. China \\ ${ }^{2}$ College of Animal Science, Fujian Agricultural and Forestry University \\ Fuzhou 350002, Fujian, P.R. China
}

\begin{abstract}
Twenty multiparous Holstein dry cows were divided randomly into four dietary groups differing in the dosage of chitosan supplementation being $0,0.1,0.2$ and $0.3 \%$ of diet dry matter for the control, treatment I, II and III, respectively. Experimental diets were fed from $60 \mathrm{~d}$ before expected calving through 15 day in milk. Mean dry matter intake of each group cows was not significantly different $(\mathrm{P}>0.05)$. Chitosan increased $(\mathrm{P}<0.05)$ the concentrations of immunoglobulin $(\operatorname{IgG}, \operatorname{IgA}$ and $\operatorname{IgM})$ in the serum of dried cows after a feeding period of 60 days. It is suggested that chitosan could be used as an immunostimulant for dry dairy cows. Concentrations of glucose in plasma of group II and III were greater $(\mathrm{P}<0.05)$ than that of control and group I. Concentration of nonesterified fatty acids in experimental groups was significantly lower $(\mathrm{P}<0.05)$ than that of a control group. Supplementation of $0.2 \%$ chitosan significantly increased $\beta$-hydroxybutyric acid concentration in plasma.
\end{abstract}

KEY WORDS: dairy cow, chitosan, immune function, blood parameters

\section{INTRODUCTION}

The dry period from late gestation to lactation is a critical phase in the production cycle of dairy cows. Optimal nutritional management during the dry period remains controversial. Successful programs would minimize health disorders and maximize productivity in the subsequent lactation. Notably, the prepartum

\footnotetext{
* Supported by the Ministry of Science and Technology of the P.R.C., No. 2006BAD04A12 Fujian Provincial Department of Science and Technology, No.2006NZ0003-1

${ }^{3}$ Corresponding author: e-mail: faulxw2000@yahoo.com.cn
} 
period is characterized by declining dry matter intake (DMI) and elevated plasma nonesterified fatty acids (NEFA) (Grummer et al., 2004). Chitosan is the deacetylated form of chitin, an aminopolysaccharide found in theexoskeleton of arthropods and certain fungi (Pittler et al., 1999). It is indigestible by mammalian digestive enzymes. Chitosan aids in the reduction of triglycerides in the liver due to its ability to bind dietary lipids, thereby reducing intestinal lipid absorption (Koide, 1998). Several studies have shown chitosan to be hypocholesterolaemic in animal models (Razdan and Petterson, 1994; Usami et al., 1994; Koide, 1998). Chitosans have been shown to alter bile acid composition, increase neutral sterol excretion and reduce ileal fat digestibility (Fukada et al., 1991; Maezaki et al., 1993; Razdan and Petterson, 1994). The mechanisms by which chitosans achieve these effects are not fully established, although increased intestinal viscosity and increased bile acid-binding capacity are two proposals currently favoured (Furda, 1990). Chitosan, which is largely deacetylated, contains cationic groups located on the polyglucosamine chain. Thus, chitosan may have a bile acid-binding capacity, causing entrapment or disintegration of mixed micelles in the duodenum and ileum (Furda,1990). This interruption in bile acid circulation would lead to reduced lipid absorption and increased sterol excretion.

The objective of this experiment was to investigate the effect of chitosan as supplement for cows in the dry period on dry matter intake, blood biochemical parameters and immune functions. It was hypothesized that alteration of plasma lipid concentrations would improve energy balance and performance of dry dairy cows.

\section{MATERIAL AND METHODS}

\section{Experimental design}

Twenty multiparous Holstein cows with similar calving date were divided randomly into four dietary groups differing in the dosage of chitosan: $0,0.1,0.2$ and $0.3 \%$ of diet dry matter (DM) for the control, treatment I, II and III, respectively. Chitosan was supplied by Nanjing Longyong Chemical Factory ( $85 \%$ deacetylated rate, its molecular weights was $50 \mathrm{k}$ Daltons). In China almost all the dairy cattle are stopped milking from $60 \mathrm{~d}$ before expected calving, so the experimental diets were fed from $60 \mathrm{~d}$ before expected calving through 15 day in milk. DMI was measured from 30 day prepartum to 2 day postpartum. Samples of maize silage and hay offered were taken on Monday, Wednesday and Friday, and samples of silage and hay refused were taken on Tuesday, Thursday and Saturday each week. Concentrate and brewer's grain samples were taken once weekly. The DMI was calculated on a daily basis. 
Experimental diets and nutritive level

According to NRC (2001) recommendation for dairy cow, the composition of basic diets and their nutritive value were as given in Table 1.

Table 1. Formula and chemical composition of diets

\begin{tabular}{lcccc}
\hline Item & \multicolumn{5}{c}{ Diets } \\
\hline Composition, $k g$ & control & I & II & III \\
\hline maize silage & 10 & 10 & 10 & 10 \\
bermuda grass hay & 2 & 2 & 2 & 2 \\
lucerne hay $_{\text {brewer's grain }}$ & 1.8 & 1.8 & 1.8 & 1.8 \\
concentrate $^{1}$ & 5 & 5 & 5 & 5 \\
chitosan, \% & 6 & 6 & 6 & 6 \\
Nutritive value & 0 & 0.1 & 0.2 & 0.3 \\
DM, kg & & & & \\
NE, MJ/kg & & & & \\
CP, g/kg & 10.72 & 10.81 & 10.90 & 11.00 \\
NDF, g/kg & 5.43 & 5.43 & 5.43 & 5.43 \\
ADF, g/kg & 131.25 & 131.25 & 131.25 & 131.25 \\
Ca, g/kg & 340.30 & 340.30 & 340.30 & 340.30 \\
P, g/kg & 216.50 & 216.50 & 216.50 & 216.50 \\
\hline
\end{tabular}

${ }^{1}$ concentrate composition, \%DM: maize 46 , barley 11 , wheat bran 5 , soyabean meal 13 , distiller's grain 10.0, cottonseed meal 6.0, sesame meal 2.0, $\mathrm{CaHPO}_{4}$ 2.0, limestone 1.0, sodium chloride 1.0, sodium bicarbonate 1.0 , potassium chloride 0.5 , magnesium oxide 0.5 , Premix 1.0

Composites were analysed using wet chemistry methods for contents of DM, CP, ADF, NDF, and minerals (Ca, P; Table 1) by Fujian Animal Nutrition Laboratory (Fuzhou, China).

\section{Sample collection and analysis}

Blood was sampled from jugular vein into EDTA or heparinized vacutainer tubes on the 2 day postpartum. Blood samples were centrifuged at $3.000 \mathrm{~g}$ for 15 min and frozen at $-20^{\circ} \mathrm{C}$ until further analysis. Plasma collected from EDTA containing tubes was analysed for NEFA, whereas plasma from heparin containing tubes was analysed for $\beta$-hydroxybutyric acid (BHBA) and glucose. Plasma NEFA, plasma glucose and BHBA were determined using the NEFA-C, plasma glucose and BHBA kits (Bioengineering Institute of Jiangcheng, Nanjing, China).

Concentrations of IgG, IgA and IgM in the serum were determined using ELISA method (Franklin et al., 1995). 


\section{Statistical analyses}

Statistical significance was tested by one-way analysis of variance (ANOVA), and when ANOVA analysis was significant the differences between means were compared using Duncan's multiple test.

\section{RESULTS}

Mean daily DMI by day relative to parturition (Table 2) decreased for all groups as parturition approached. Hayirli et al. (2003) reported a 32\% decline in DMI for multiparous Holstein cows during the transition period. The supplementation of the diets by chitosan did not change DMI.

Table 2. Mean daily by days relative to parturition, $\mathrm{kg} / \mathrm{d}$

\begin{tabular}{|c|c|c|c|c|c|}
\hline \multirow{2}{*}{$\begin{array}{l}\text { Days to } \\
\text { parturition }\end{array}$} & \multicolumn{4}{|c|}{ Groups } & \multirow{2}{*}{ SEM } \\
\hline & control & I & II & III & \\
\hline-30 & 12.68 & 12.78 & 12.28 & 12.48 & 0.08 \\
\hline-23 & 12.24 & 12.28 & 11.98 & 12.18 & 0.13 \\
\hline-16 & 12.00 & 12.00 & 11.72 & 11.96 & 0.09 \\
\hline-9 & 12.08 & 12.08 & 11.82 & 12.08 & 0.11 \\
\hline 2 & 10.58 & 10.64 & 10.24 & 10.46 & 0.05 \\
\hline
\end{tabular}

On the other hand, the levels of IgG, IgA, IgM in the serum of chitosan groups were higher $(\mathrm{P}>0.05$; Table 3$)$ than that of the control group.

Table 3. The effect of chitosan on immunoglobulins in the serum of cows

\begin{tabular}{lccccc}
\hline \multirow{2}{*}{ Item } & \multicolumn{3}{c}{ Groups } & \multirow{2}{*}{ SEM } \\
\cline { 2 - 5 } & control & I & II & III & \\
\hline IgG & $2.51^{\mathrm{a}}$ & $3.19^{\mathrm{b}}$ & $3.31^{\mathrm{b}}$ & $3.69^{\mathrm{c}}$ & 0.58 \\
IgA & $0.18^{\mathrm{a}}$ & $0.28^{\mathrm{b}}$ & $0.26^{\mathrm{b}}$ & $0.37^{\mathrm{c}}$ & 0.03 \\
IgM & $0.83^{\mathrm{a}}$ & $0.99^{\mathrm{b}}$ & $1.21^{\mathrm{c}}$ & $1.23^{\mathrm{c}}$ & 0.19 \\
\hline
\end{tabular}

means having different superscripts in a row differ significantly at $\mathrm{P}<0.05$

Table 4. The effect of chitosan on plasma glucose, NEFA, and BHBA of dried cows

\begin{tabular}{lrrrrr}
\hline \multirow{2}{*}{ Item } & \multicolumn{4}{c}{ Groups } & \multirow{2}{*}{ SEM } \\
\cline { 2 - 5 } & control & \multicolumn{1}{c}{ I } & \multicolumn{1}{c}{ II } & \multicolumn{1}{c}{ III } & \\
\hline Glucose, $\mathrm{mg} / \mathrm{dl}^{*}$ & $62.21^{\mathrm{a}}$ & $69.43^{\mathrm{ab}}$ & $73.82^{\mathrm{b}}$ & $75.04^{\mathrm{b}}$ & 4.33 \\
NEFA, $\mu \mathrm{Eq} / 1^{*}$ & $526.83^{\mathrm{a}}$ & $478.01^{\mathrm{b}}$ & $480.62^{\mathrm{b}}$ & $474.20^{\mathrm{b}}$ & 28.09 \\
BHBA, mg/d1* & $8.44^{\mathrm{a}}$ & $9.06^{\mathrm{ab}}$ & $9.40^{\mathrm{ab}}$ & $10.10^{\mathrm{b}}$ & 1.15 \\
\hline
\end{tabular}

means having different superscripts in a row differ significantly at $\mathrm{P}<0.05$ 
Postpartum concentrations of glucose in plasma of group II and III were higher $(\mathrm{P}<0.05)$ than in the control and group I. On the other hand, the concentration of NEFA in chitosan groups was lower $(\mathrm{P}<0.05)$ than in a control group. Animals fed more chitosan had lower plasma NEFA concentrations.

Although feeding cows chitosan increased BHBA concentrations in plasma, it did not become significant until added $0.2 \%$ chitosan.

\section{DISCUSSION}

Chitosan supplementation did not affect DMI during the prepartum period. As parturition approached, DMI decreased for all dry cows. These data are consistent with previously reported decreases in DMI during the final days before calving, which have been reported to be on average about 30\% from those earlier in the dry period (Grummer et al., 2004). In our study cows, regardless of diet, maintained DMI as parturition approached and neither variable decreased until the 2 days after calving.

On the other hand the levels of $\operatorname{IgG}, \operatorname{IgA}$, IgM in the experimental groups were higher than those in the control group, and it may suggest that chitosan could have had some effects on the immunological system of the cows. However, the mechanism of how dietary chitosan influences these factors are not known yet. Much more work should be done in this aspect.

NEFA are used for energy by body tissues and as precursors for synthesis of milk fat; however, available data suggest that the liver takes up NEFA in proportion to their supply (Emery et al., 1992). Unfortunately, the liver typically does not have sufficient capacity to completely dispose of NEFA through export into the blood or catabolism for energy, and thus dry cows are predisposed to accumulate triglycerides in the liver tissue. The primary consequence of this triglyceride accumulation appears to be impaired liver function, including decreased capacity for ureagenesis and gluconeogenesis.

Management of NEFA during the dry period is an important factor influencing liver health, the capacity of liver to make glucose, and metabolic disorder incidence in dry cows. Data supporting that chitosan supplementation to the diet decreases plasma concentrations of NEFA are differed significantly. The lower NEFA values indicate that there is less fat mobilization in these cows (Grummer, 1993), whereas the higher plasma BHBA and glucose values suggest that there are improved energy balance and greater ability to maintain blood glucose concentrations, consistent with demands for lactation and the perceived goals of nutrition for the dry dairy cow. 


\section{CONCLUSIONS}

The results of this study show that there is a benefit in terms of improved immunoglobulin (IgG, IgA and IgM), glucose and $\beta$-hydroxybutyric acid at calving to increasing the chitosan supplementation propotion in the dry period. A more favourable profile was considered to be lower plasma concentrations of nonesterified fatty acids. Increasing chitosan density of diets was not associated with increased or decreased dry matter intake.

\section{REFERENCES}

Emery R.S., Liesman J.S., Herdt T.H., 1992. Metabolism of long-chain fatty acids by ruminant liver. J. Nutr. 122, 832-837

Franklin S.T., Young J.W., Nonnecke B.J., Horst R.L., 1995.Administration of 13-cis retinoic acid to dairy cattle: 2. Phenotype of blood leukocytes and production of immunoglobulin. J. Dairy Sci. 78,70-76

Fukada Y., Kimura K., Ayaki Y., 1991. Effect of chitosan feeding on intestinal bile acid metabolism in rats. Lipids 26, 395-399

Furda I., 1990. Interaction of dietary fiber with lipids - mechanistic theories and their limitations. In: I. Furda, C.J. Brine (Editors). New Developments in Dietary Fiber. New York, Plenum Press, pp. 67-82

Grummer R.R., 1993. Etiology of lipid-related metabolic disorders in periparturient dairy cows. J. Dairy Sci. 76, 3882-3896

Grummer R.R., Mashek D.G., Hayirli A., 2004. Dry matter intake and energy balance in the transition period. Vet. Clin. North Amer. Food Anim. Pr. 20, 447-470

Hayirli A., Grummer R.R., Nordheim E.V., Crump P.M., 2003. Models for predicting dry matter intake of Holsteins during the prefresh transition period. J. Dairy Sci. 86, 1771-1779

Koide S.S., 1998. Chitin-chitosan: properties, benefits and risks. Nutr. Res. 8, 1091-1101

Maezaki Y., Tsuji K., Nakagawa Y., Kawai Y., Akimoto M., 1993. Hypocholesterolemic effect of chitosan in adult males. Biosci. Biotechnol. Biochem. 57, 1439-1444

NRC, 2001. Nutrient Requirements of Dairy Cattle. National Research Council. 7th revised Edition. National Academy of Sciences. Washington, DC

Pittler M.H., Abbot N.C., Harkness E.F., Ernst E., 1999. Randomized, double-blind trial of chitosan for body weight reduction. Eur. J. Clin. Nutr. 53, 379-381

Razdan A., Petterson O., 1994. Effect of chitin and chitosan on nutrient digestibility and plasma lipid concentrations in broiler chicken. Brit. J. Nutr. 72, 277-288

Usami Y., Okamoto Y., Minami S., Matsuhashi A., Kumazawa N.H., Tonioka S., Shigemasa Y., 1994. Migration of canine neutrophiles of chitin and chitosan. J. Vet. Med. Sci. 56, 1215-1216 